\title{
Multi-index method using offshore ocean-bottom pressure data for real-time tsunami forecast
}

\author{
Naotaka Yamamoto* ${ }^{*}$, Shin Aoi, Kenji Hirata, Wataru Suzuki, Takashi Kunugi and Hiromitsu Nakamura
}

\begin{abstract}
We developed a real-time tsunami forecast method using only pressure data collected from the bottom of the ocean via a dense offshore observation network. The key feature of the method is rapid matching between offshore tsunami observations and pre-calculated offshore tsunami spatial distributions. We first calculate the tsunami waveforms at offshore stations and the maximum coastal tsunami heights from any possible tsunami source model and register them in the proposed Tsunami Scenario Bank (TSB). When a tsunami occurs, we use multiple indices to quickly select dozens of appropriate tsunami scenarios that can explain the offshore observations. At the same time, the maximum coastal tsunami heights coupled with the selected tsunami scenarios are forecast. We apply three indices, which are the correlation coefficient and two kinds of variance reductions normalized by the L2-norm of either the observation or calculation, to match the observed spatial distributions with the pre-calculated spatial distributions in the TSB. We examine the ability of our method to select appropriate tsunami scenarios by conducting synthetic tests using a scenario based on "pseudo-observations." For these tests, we construct a tentative TSB, which contains tsunami waveforms at locations in the Seafloor Observation Network for Earthquakes and Tsunamis along the Japan Trench and maximum coastal tsunami heights, using about 2000 tsunami source models along the Japan Trench. Based on the test results, we confirm that the method can select appropriate tsunami scenarios within a certain precision by using the two kinds of variance reductions, which are sensitive to the tsunami size, and the correlation coefficient, which is sensitive to the tsunami source location. In this paper, we present the results and discuss the characteristics and behavior of the multi-index method. The addition of tsunami inundation components to the TSB is expected to enable the application of this method to real-time tsunami inundation forecasts in the near future.
\end{abstract}

Keywords: Real-time tsunami forecast, Multi-index, Variance reduction, Tsunami Scenario Bank, S-net

\section{Introduction}

A wide variety of methods for near-field tsunami forecasts have been proposed. These methods depend on the purpose and type of observational data (e.g., Tsushima and Ohta 2014). Here we define a "real-time tsunami forecast" to derive the information required for evacuation before the first arrival of a tsunami at the coast. In Japan, a real-time tsunami forecast using the hypocenter location and the earthquake magnitude determined from land-based seismological observation has been operated

*Correspondence: naotaka.yamamoto@bosai.go.jp National Research Institute for Earth Science and Disaster Resilience (NIED), 3-1 Tennodai, Tsukuba, Ibaraki 305-0006, Japan by the Japan Meteorological Agency (JMA) since 1999 (Tatehata 1997; Kamigaichi 2009). This is used as an initial forecast because it can be issued very quickly. However, it contains considerable uncertainty, because land-based seismic observation alone cannot constrain the hypocenter location and the magnitude of subduction zone earthquakes. Accordingly, a more accurate real-time tsunami forecast method using fault geometry information and the average amount of slip determined by the Global Navigation Satellite System (GNSS) was proposed by Blewitt et al. (2009). Moreover, the centroid moment tensor for a more accurate tsunami forecast could be estimated by W-phase waveform inversions (Benavente and Cummins 2013; Gusman and Tanioka 
2014). Because the fault model is obtained from GNSS data and/or W-phase records within a few minutes after an earthquake occurs, it is possible to replace the initial forecast information with more accurate information (Tsushima and Ohta 2014). In addition, a tsunami forecast method to estimate the best tsunami source model by inversion analysis of tsunami waveform data from ocean-bottom pressure gauges was proposed by Tsushima et al. (2009). In their method, the arrival times and amplitudes of tsunamis at the coasts are forecast by linearly combining pre-calculated Green's functions. However, obtaining direct measurements of tsunamis requires more time to detect tsunami signals than obtaining seismic wave or real-time GNSS data (Tsushima and Ohta 2014, Figure 4). Attempting a breakthrough, Baba et al. (2014) investigated the correlation between offshore and coastal tsunami heights by using ocean-bottom pressure data from the Dense Oceanfloor Network system for Earthquakes and Tsunamis (DONET) observation array (Kaneda et al. 2009). They successfully forecast the coastal tsunami height within $10 \mathrm{~min}$ after the occurrence of an earthquake by concentrating on predicting the tsunami scale. In addition, Yamamoto et al. (2016) proposed a rapid method to estimate the tsunami source location using a dense offshore observation network. They claimed that this location could be estimated within a few minutes after the occurrence of an earthquake by using the tsunami centroid location (TCL). Although direct measurements of tsunamis are used in their method, the required estimation time is comparable to that achieved using real-time GNSS data. It is possible to replace the earthquake location and magnitude with the tsunami source location estimated by Yamamoto et al. (2016) and the tsunami scale estimated by Baba et al. (2014) for the initial tsunami warning. Moreover, Maeda et al. (2015) proposed a tsunami forecast method based on a data assimilation technique using a dense offshore observation network rather than using seismic source parameters or the initial height of the sea surface. In their method, the tsunami wavefield including offshore tsunami height and velocity will be available as initial conditions for other tsunami forecasting methods such as tFISH (Tsushima et al. 2009), NearTIF (Gusman et al. 2014) to calculate the inundation or run-up for real-time forecasting. For a real-time tsunami inundation forecast, some researchers have proposed new methods that use on-demand forward simulations with inverted tsunami source models (Tatsumi and Tomita 2013; Koshimura et al. 2014; Oishi et al. 2015). However, these methods are computationally expensive; hence, the coastal region to be included in the forecast is limited. A real-time tsunami inundation forecast on high-resolution topography was achieved by Gusman et al. (2014), who proposed a new method that requires pre-calculated tsunami waveforms and tsunami inundation at near-shore points in advance of the occurrence of an earthquake. Their method involves the selection of the best-matched tsunami scenario by comparing pre-calculated tsunami waveforms and synthetic tsunami waveforms calculated using forecast tsunami source information, such as fault models estimated by the Real-time Automatic detection method for Permanent Displacement (RAPiD) proposed by Ohta et al. (2012), W-Phase data (Kanamori 1993; Gusman and Tanioka 2014), or initial sea-surface displacement distributions (Tsushima et al. 2009). The pre-calculated tsunami inundation for the best-matched tsunami scenario is then forecast.

We propose a new approach for real-time tsunami inundation forecasts that uses only tsunami data obtained by offshore ocean-bottom pressure gauges without using any seismological observation data. Consequently, it is possible to predict tsunamis by avoiding the influence of estimation errors in the hypocenter location or the earthquake magnitude determined by seismological observations. For tsunami earthquakes, which are defined as events in which the size of the tsunami is significantly larger than that expected from seismic waves (Kanamori 1972), it is possible to appropriately evaluate the size of the tsunami irrespective of the earthquake magnitude estimated by seismological observations. In addition, to provide high-resolution tsunami inundation forecasts for a wide coastal zone, we use a pre-calculated database rather than on-demand forward simulation. If we could consider all possible tsunami scenarios, the tsunami forecast would be highly precise. However, the number of tsunami scenarios that can be prepared is limited because of a finite amount of time and limited computing resources. In other words, a tsunami scenario selected from pre-calculated tsunami scenarios cannot always make correct predictions for an entire coastal region. Therefore, we select dozens of tsunami scenarios that can explain offshore observation data within acceptable thresholds in order to express the uncertainties of a tsunami forecast. Another basic concept of our approach is that the real-time tsunami forecast is derived directly from observed tsunami data without any information about the tsunami source, which is generally obtained by inversion and can contain large uncertainties.

In this paper, we propose the use of multiple indices to select appropriate tsunami scenarios. The first stage of our method involves the preparation of a Tsunami Scenario Bank (TSB), which contains tsunami waveforms at offshore stations and coastal tsunami information calculated using a number of possible tsunami source models. When a tsunami occurs, we use three indices to quickly select dozens of appropriate tsunami 
scenarios that can explain the offshore observations. At the same time, the coastal tsunami information coupled with the selected tsunami scenarios is forecast. The three indices are a correlation coefficient and two kinds of variance reductions and are used to compare the observed waveforms and the pre-calculated waveforms in the TSB. We conducted an evaluation to determine whether our method can select appropriate tsunami scenarios by considering real-time oceanbottom hydrostatic pressure data that are expected to be obtained by the Seafloor Observation Network for Earthquakes and Tsunamis (S-net) (Uehira et al. 2012; Kanazawa 2013), which is a dense and large-scale offshore observation network under construction along the Japan Trench by the National Research Institute for Earth Science and Disaster Resilience (NIED). We constructed a tentative TSB by calculating offshore tsunami waveforms at the $S$-net instrument locations, and the maximum coastal tsunami heights along the Pacific coast of Kanto, Tohoku, and Hokkaido using about 2000 tsunami source models, which were previously prepared for a probabilistic tsunami hazard assessment in the Japan Trench region (Hirata et al. 2014). Furthermore, we discuss the characteristics and behavior of the multiindex approach in the matching procedure.

\section{Matching method}

Here we describe a method for comparing the observed waveform $O\left(\boldsymbol{r}_{i}, t\right)$ and the pre-calculated waveform $C\left(\boldsymbol{r}_{i}, t\right)$ registered in the TSB, for the $i$ th observation station at a position $\boldsymbol{r}_{i}$ after time $t$ has elapsed following an earthquake.

\section{Three indices}

As mentioned above, we use three indices, the correlation coefficient and two kinds of variance reductions, to compare $O\left(\boldsymbol{r}_{i}, t\right)$ to $C\left(\boldsymbol{r}_{i}, t\right)$. The correlation coefficient $\mathrm{R}(t)$, which is a function of time $t$, is defined as follows:

$$
\mathrm{R}(t)=\frac{\sum_{i=1}^{n} O\left(\boldsymbol{r}_{i}, t\right) C\left(\boldsymbol{r}_{i}, t\right)}{\sqrt{\sum_{i=1}^{n} O^{2}\left(\boldsymbol{r}_{i}, t\right)} \sqrt{\sum_{i=1}^{n} C^{2}\left(\boldsymbol{r}_{i}, t\right)}},
$$

where $\mathrm{n}$ is the number of observation stations. Equation (1) indicates that $\mathrm{R}(t)$ is the cosine of the angle formed by two n-dimensional vectors, $O\left(\boldsymbol{r}_{i}, t\right)$ and $C\left(\boldsymbol{r}_{i}, t\right)$, and $\mathrm{R}(t)$ has a maximum value of 1 when $O\left(\boldsymbol{r}_{i}, t\right)$ is similar to $C\left(\boldsymbol{r}_{i}, t\right)$. When $O\left(\boldsymbol{r}_{i}, t\right)$ and $C\left(\boldsymbol{r}_{i}, t\right)$ are completely opposite, $\mathrm{R}(t)$ becomes -1 , i.e., $\mathrm{R}(t)$ ranges from -1 to 1 . $\mathrm{R}(t)$ is expected to be sensitive to the tsunami source location, because $\mathrm{R}(t)$ strongly depends on the spatial distribution of $O\left(\boldsymbol{r}_{i}, t\right)$ and $C\left(\boldsymbol{r}_{i}, t\right)$. However, $\mathrm{R}(t)$ is close to 1 when their spatial distributions are similar, even though the amplitudes of $O\left(\boldsymbol{r}_{i}, t\right)$ and $C\left(\boldsymbol{r}_{i}, t\right)$ are very different.
Next, we define the variance reduction to discriminate between acceptable and unacceptable matching accuracy. In general, the variance reduction is defined as follows:

$$
\text { Variance reduction }=1-\frac{\text { Difference }}{\text { Reference amount }} .
$$

In this study, we define two variance reductions, $\operatorname{VRO}(t)$ and $\operatorname{VRC}(t)$, as functions of time $t$ normalized by the L2-norm of either the observed waveform $O\left(\boldsymbol{r}_{i}, t\right)$ or the calculated waveform $C\left(\boldsymbol{r}_{i}, t\right)$, as follows:

$$
\begin{gathered}
\operatorname{VRO}(t)=1-\frac{\sum_{i=1}^{n}\left(O\left(\boldsymbol{r}_{i}, t\right)-C\left(\boldsymbol{r}_{i}, t\right)\right)^{2}}{\sum_{i=1}^{n} O^{2}\left(\boldsymbol{r}_{i}, t\right)} \\
\operatorname{VRC}(t)=1-\frac{\sum_{i=1}^{n}\left(O\left(\boldsymbol{r}_{i}, t\right)-C\left(\boldsymbol{r}_{i}, t\right)\right)^{2}}{\sum_{i=1}^{n} C^{2}\left(\boldsymbol{r}_{i}, t\right)},
\end{gathered}
$$

where we use the sum of the squared residual as the difference in Eq. (2). As defined by Eqs. (3) and (4), both variance reductions become 1 when $O\left(\boldsymbol{r}_{i}, t\right)$ equals $C\left(\boldsymbol{r}_{i}, t\right)$, i.e., variance reductions of 1 indicate the best matches. These values become smaller as the difference between $O\left(\boldsymbol{r}_{i}, t\right)$ and $C\left(\boldsymbol{r}_{i}, t\right)$ increases. Therefore, $\operatorname{VRO}(t)$ and $\operatorname{VRC}(t)$ range from $-\infty$ to 1 .

Next, we rewrite Eqs. (3) and (4) as

$$
\begin{aligned}
\operatorname{VRO}(t) & =R^{2}(t)-(\alpha(t)-\mathrm{R}(t))^{2} \\
& =-\alpha^{2}(t)+2 R(t) \alpha(t) \\
\operatorname{VRC}(t) & =R^{2}(t)-\frac{(1-\mathrm{R}(t) \alpha(t))^{2}}{\alpha^{2}(t)} \\
& =-\frac{1}{\alpha^{2}(t)}+2 \frac{R(t)}{\alpha(t)},
\end{aligned}
$$

where $\alpha(t)$ is defined as follows:

$$
\alpha(t)=\sqrt{\frac{\sum_{i=1}^{n} C^{2}\left(\boldsymbol{r}_{i}, t\right)}{\sum_{i=1}^{n} O^{2}\left(\boldsymbol{r}_{i}, t\right)}},
$$

which is the square root of the ratio of the L2-norm of $C\left(\boldsymbol{r}_{i}, t\right)$ to the L2-norm of $O\left(\boldsymbol{r}_{i}, t\right)$ and is larger than 0 $(\alpha(t)>0)$. Figure 1 shows $\operatorname{VRO}(t)$ and $\operatorname{VRC}(t)$ as functions of $\alpha(t)$ for fixed values of $\mathrm{R}(t)$ in Eqs. (5) and (6). When $\alpha(t)$ is significantly larger than 1, i.e., the sum of the squares of $C\left(\boldsymbol{r}_{i}, t\right)$ is larger than the sum of the squares of $O\left(\boldsymbol{r}_{i}, t\right), \operatorname{VRO}(t)$ has a large negative value that is proportional to the square of $\alpha(t)$, as given in Eq. (5). A large $\alpha(t)$ indicates that $C\left(\boldsymbol{r}_{i}, t\right)$ is overestimated with respect to $O\left(\boldsymbol{r}_{i}, t\right)$. On the other hand, an $\alpha(t)$ value that is significantly smaller than 1 indicates that $C\left(\boldsymbol{r}_{i}, t\right)$ is underestimated with respect to $O\left(\boldsymbol{r}_{i}, t\right)$. In this case, $\operatorname{VRC}(t)$ has 


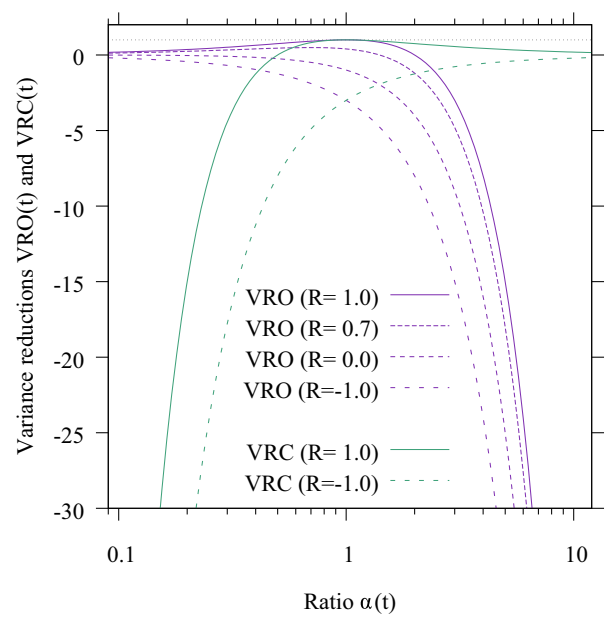

Fig. 1 Variance reductions, $\operatorname{VRO}(t)$ and $\operatorname{VRC}(t)$, as functions of $\alpha(t)$. Cases of $R(t)=-1.0,0.0,0.7$, and 1.0 are displayed

a large negative value that is proportional to the inverse of the square of $\alpha(t)$, as shown in Eq. (6). From the above considerations, we clearly find that $\operatorname{VRO}(t)$ and $\operatorname{VRC}(t)$ are sensitive to overestimation and underestimation of $C\left(\boldsymbol{r}_{i}, t\right)$ with respect to $O\left(\boldsymbol{r}_{i}, t\right)$.

Figure 2 shows the relations among the variance reductions, $\operatorname{VRO}(t)$ and $\operatorname{VRC}(t)$, the correlation coefficient $\mathrm{R}(t)$, and the ratio $\alpha(t)$. All possible pairs of $\operatorname{VRO}(t)$ and $\operatorname{VRC}(t)$ are plotted between the purple curves, which indicate $\mathrm{R}(t)=1$, and the light blue curve, which indicates $\mathrm{R}(t)=-1$. The red and orange lines show pairs of $\operatorname{VRO}(t)$ and $\operatorname{VRC}(t)$ with $\alpha(t)$ values of $0.5,1.0$, and 2.0.

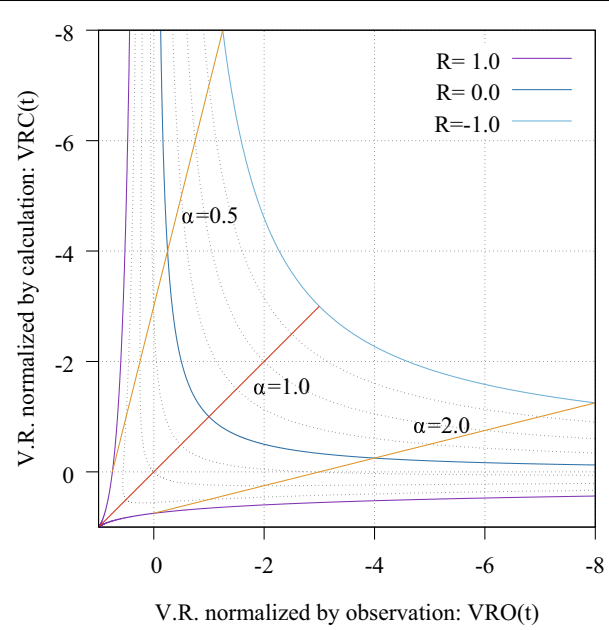

Fig. 2 Relations between the three indices [two variance reductions, $\operatorname{VRO}(t)$ and $\operatorname{VRC}(t)$, and correlation coefficient $R(t)]$ and the ratio $\alpha(t)$ in $\operatorname{VRO}(t)-\operatorname{VRC}(t)$ diagram. All possible pairs of all scenarios are restricted to the region between the curves of $R(t)=1.0$ and $R(t)=-1.0$

\section{Waveform conversion}

We avoid the mismatch caused by wave phase differences by using the maximum value of the absolute values of the observed waveforms $O_{\text {converted }}\left(\boldsymbol{r}_{i}, t\right)$, defined as follows:

$$
O_{\text {converted }}\left(\boldsymbol{r}_{i}, t\right)=\max _{t^{\prime} \leq t}\left|O\left(\boldsymbol{r}_{i}, t^{\prime}\right)\right| .
$$

The converted values become constant after a sufficient time lapse following an earthquake. We also apply the same conversion to the calculated waveform $C\left(\boldsymbol{r}_{i}, t\right)$ as follows:

$$
C_{\text {converted }}\left(\boldsymbol{r}_{i}, t\right)=\max _{t^{\prime} \leq t}\left|C\left(\boldsymbol{r}_{i}, t^{\prime}\right)\right| .
$$

When we compare the converted waveforms $O_{\text {converted }}$ $\left(\boldsymbol{r}_{i}, t\right)$ and $C_{\text {converted }}\left(\boldsymbol{r}_{i}, t\right)$, the correlation coefficient $\mathrm{R}(t)$ never becomes negative, i.e., $\mathrm{R}(t)$ ranges from 0 to 1 .

\section{Construction of a tentative TSB}

In this study, we set up 1890 tsunami source models, which can affect the Pacific coast of Kanto, Tohoku, and Hokkaido, in the region of the Japan Trench. The models, which were previously prepared for probabilistic tsunami hazard assessment (Hirata et al. 2014), are used to construct a tentative TSB. We then calculate synthetic offshore tsunami waveforms $\eta\left(\boldsymbol{r}_{i}, t\right)$ for 150 stations of S-net by solving nonlinear long-wave equations using a staggered leapfrog finite-difference scheme. We use nesting grid systems with a minimum size of $50 \mathrm{~m}$ for the land side that corresponds to the target coastline shown as the blue line in Fig. 3, and larger mesh sizes of 150, 450, and $1350 \mathrm{~m}$ for the sea side. A run-up boundary condition is applied to the coastal regions, and an open boundary condition is applied to the rims of the 1350-m mesh systems. In these calculations, we assume that the seasurface displacement is the same as the vertical seafloor displacement of coseismic crustal deformation caused by an earthquake, and the sea-surface displacement is immediately completed at time $t=0$. The calculated tsunami waveforms $\eta\left(\boldsymbol{r}_{i}, t\right)$ are converted to ocean-bottom hydrostatic pressure changes $C\left(\boldsymbol{r}_{i}, t\right)$ as follows:

$$
C\left(\boldsymbol{r}_{i}, t\right)=\rho g\left(\eta\left(\boldsymbol{r}_{i}, t\right)-\eta_{0}\left(\boldsymbol{r}_{i}\right)\right),
$$

where $\rho$ is the average density of seawater, $g$ is the gravitational acceleration, and $\eta_{0}\left(\boldsymbol{r}_{i}\right)$ is the initial sea-surface displacement, which is the same as the permanent seafloor deformation calculated by Okada's formula (Okada 1985). We also assume that the hydrostatic oceanbottom pressure, which is proportional to the total water depth, does not change during an earthquake, i.e., $C\left(\boldsymbol{r}_{i}, t=0\right)=0$, because the ocean-bottom pressure gauges are displaced by seafloor deformation equal to the sea-surface displacement. Finally, we register the 


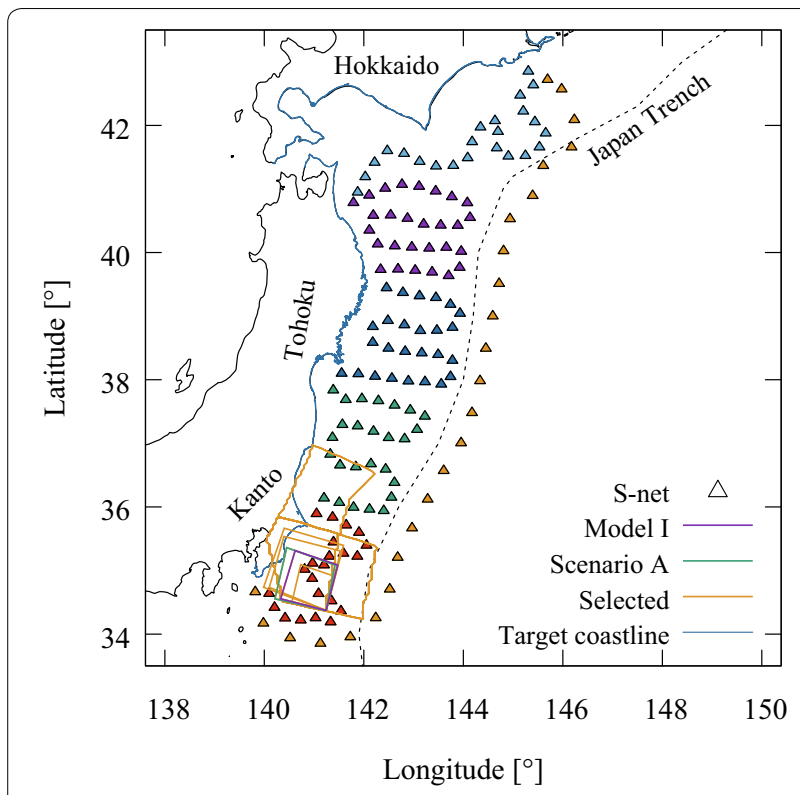

Fig. 3 Fault models of 16 tsunami scenarios selected by the multiindex method for Model I. These scenarios are selected at 5 min after the earthquake occurrence by comparing with Model I, whose fault model is shown as the purple polygon. The green polygon indicates the fault model of the best-matched tsunami scenario, described as scenario $A$ in the text. The orange polygons indicate 14 other selected fault models. The color triangles show the ocean-bottom pressure gauges of the S-net. The blue lines show the target coastline in this study along the Pacific coast of Kanto, Tohoku, and Hokkaido

calculated waveform $C\left(\boldsymbol{r}_{i}, t\right)$ with its fault model and the maximum coastal tsunami heights along the Pacific coast of Kanto, Tohoku, and Hokkaido shown as the blue line in Fig. 3 in the tentative TSB.

\section{Case studies and evaluations}

We investigated whether it is possible to select appropriate tsunami scenarios from the tentative TSB by using the three indices defined in Eqs. (1), (3), and (4) with the maximum absolute values defined in Eqs. (8) and (9). Moreover, we also assumed that specified synthetic observed waveforms are "pseudo-observation" waveforms because the $\mathrm{S}$-net has not yet recorded actual tsunami observation data. We then examine the selected tsunami scenarios by comparing the maximum coastal tsunami height distributions of the pseudo-observation scenarios and the selected tsunami scenarios. In this section, we describe the results of these examinations.

\section{Examination using a tsunami scenario in the TSB (Model I)}

As the first pseudo-observation scenario, named Model I, we choose a Mw 8.0 earthquake that occurred off the Boso Peninsula in the Kanto region, where the plate interface was not ruptured by the 2011 Tohoku earthquake.
This fault model is shown as a purple polygon in Fig. 3. Our multi-index method selects 16 tsunami scenarios under the criteria of VRO $(t=5 \mathrm{~min}) \geq 0.0$, VRC $(t=5 \mathrm{~min}) \geq 0.0$, and $\mathrm{R}(t=5 \mathrm{~min}) \geq 0.7$ as illustrated in Fig. 3. Figure 4a compares the pseudo-observation waveform $O\left(\boldsymbol{r}_{i}, t=5 \mathrm{~min}\right)$ and the best-matched tsunami scenario, named scenario $\mathrm{A}$, waveform $C\left(\boldsymbol{r}_{i}, t=5 \mathrm{~min}\right)$, which is represented by the green polygon in Fig. 3 and the green square in Fig. 4c. Figure $4 b$ compares the converted pseudo-observation waveforms with that of scenario A. Figure 4c, d plots the selected tsunami scenarios on the VRO-VRC diagram. The scenario shown at $(\operatorname{VRO}(t=5 \mathrm{~min}), \operatorname{VRC}(t=5 \mathrm{~min}))=(1,1)$ in Fig. $4 \mathrm{c}$ represents Model I. From Fig. 4d, which shows a wider range of the VRO-VRC diagram, we can see that many unselected tsunami scenarios are plotted along the $\mathrm{R}$ $(t=5 \mathrm{~min})=0.0$ curve, i.e., many tsunami scenarios registered in the tentative TSB do not satisfy the threshold $\mathrm{R}(t=5 \mathrm{~min}) \geq 0.7$. Figure 5 is a color contour map for $\mathrm{R}$ $(t=5 \mathrm{~min})$ plotted at the centroid location of the slip distribution of fault models registered in the TSB. The figure suggests that the calculated scenarios with $\mathrm{R}(t)$ close to zero are far from the location of the fault model of the pseudo-observation scenario, i.e., $\mathrm{R}(t)$ is sensitive to the tsunami source location.

Figure 6 shows the evaluations for maximum coastal tsunami height distribution for Model I. Figure 6a indicates the maximum coastal tsunami height distributions of Model I (red line) and 16 selected tsunami scenarios (gray lines) along the coastline of Kanto, Tohoku, and Hokkaido represented by the blue line in Fig. 3. A variety of maximum coastal tsunami height distributions shown as gray lines in Fig. 6a, which indicate overestimation and underestimation by Model I, could express the uncertainties of a tsunami forecast. We evaluated the extent to which the selected tsunami scenarios were able to approximate the pseudo-observation scenario by using the three indices defined by Eqs. (1), (3), and (4) to compare the maximum coastal tsunami height distributions of the pseudo-observation scenario with those of the selected tsunami scenarios. In this study, we refer to the coastal indices as coastal $\mathrm{R}$, coastal VRO, and coastal VRC, which are defined by the pseudo-observation distributions and the calculated distributions of maximum coastal tsunami heights that do not depend on time $t$. Figure $6 \mathrm{~b}$ plots 16 selected tsunami scenarios on the coastal VRO-VRC diagram for comparing the maximum coastal tsunami height distributions for the corresponding tsunami scenarios. In this figure, the colored squares indicate the selected tsunami scenarios whose colors are the same as those of Fig. 4c, and the gray crosses indicate the unselected tsunami scenarios. 

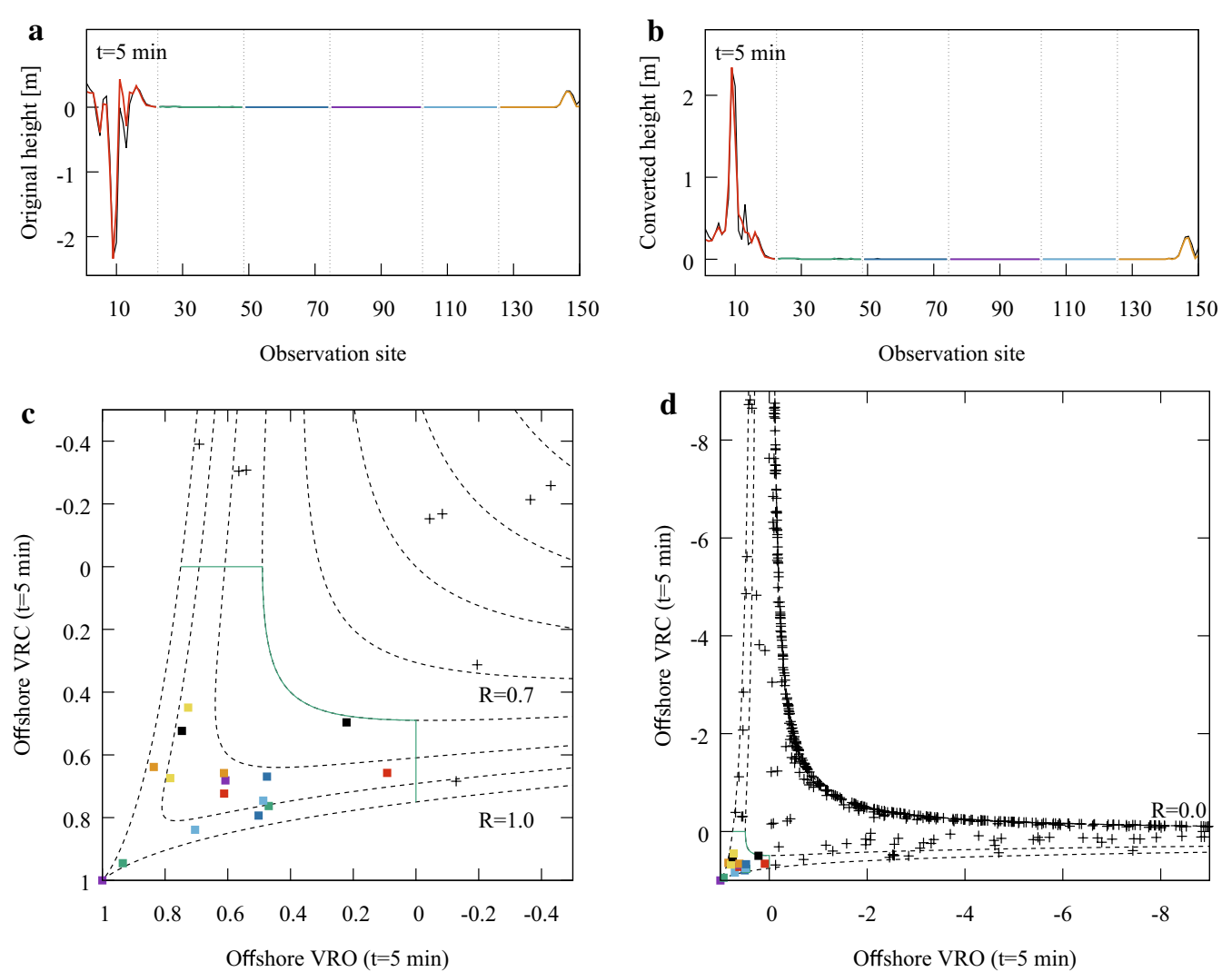

Fig. 4 Offshore comparisons at 5 min after the occurrence of an earthquake for Model I. a Compares the tsunami height distributions $\left[\eta\left(\boldsymbol{r}_{i}, t=5 \mathrm{~min}\right)-\eta_{0}\left(\boldsymbol{r}_{i}\right) ; i=1 \ldots 150\right.$ in Eq. (10)] of Model I (colored lines) with those of scenario A (gray line). $\mathbf{b}$ Compares the distributions in the converted wave height changes $\left[O_{\text {converted }}\left(\boldsymbol{r}_{i}, t=5 \mathrm{~min}\right) / \rho g\right.$ and $C_{\text {converted }}\left(\boldsymbol{r}_{i}, t=5 \mathrm{~min}\right) / \rho \mathrm{g}$ in Eqs. (8) and (9)]. The line colors used for Model I are the same as those of the $\mathrm{S}$-net shown as triangles in Fig. 3. c, d A close-up plot around the criteria and a wide view of the VRO-VRC diagram, respectively. The area surrounded by the green curves indicates the applied criteria, VRO $(t=5 \mathrm{~min}) \geq 0.0, \mathrm{VRC}(t=5 \mathrm{~min}) \geq 0.0$, and $\mathrm{R}(t=5 \mathrm{~min}) \geq 0.7$. The colored squares represent the selected tsunami scenarios, and the gray crosses represent the unselected tsunami scenarios. The pseudo-observation scenario and scenario A are represented by the purple square at $(1,1)$ and the green square at $(0.94,0.95)$ in $\mathbf{c}$, respectively

The use of $t=5 \mathrm{~min}$ is reasonable and appropriate for near-field forecasting, e.g., in the Kanto region, because a real-time forecast is needed for evacuation purposes before the first arrival of a tsunami at the coast. However, it is still reasonable and appropriate to use $t=10 \mathrm{~min}$ for the Tohoku and Hokkaido regions. We next investigate the selected tsunami scenarios $10 \mathrm{~min}$ after the occurrence of an earthquake using the same criteria that were used in the previous examination: VRO $(t=10 \mathrm{~min}) \geq 0.0$, VRC $(t=10 \mathrm{~min}) \geq 0.0$, and $\mathrm{R}(t=10 \mathrm{~min}) \geq 0.7$. We confirm that 7 of the 16 tsunami scenarios selected at $t=5$ min comply with the criteria at $t=10 \mathrm{~min}$ and the best-matched tsunami scenario, which is represented by the green polygon and square in Figs. 3 and 4c, is selected as the bestmatched scenario at $t=10 \mathrm{~min}$. We also confirm that the uncertainty in the set of selected tsunami scenarios is reduced because seven selected tsunami scenarios are matched in the coastal $\mathrm{VRO} \geq 0.89, \mathrm{VRC} \geq 0.85$, and $\mathrm{R}$ $(t=10 \mathrm{~min}) \geq 0.95$ (see Fig. 4c). However, the other scenario, which is not selected at $t=5 \mathrm{~min}$, satisfies the criteria at $t=10 \mathrm{~min}$ with (VRO $(t=10 \mathrm{~min})$, VRC $(t=10 \mathrm{~min}), \mathrm{R}(t=10 \mathrm{~min}))=(0.78,0.30,0.97)$. The three indices indicate that this scenario is selected as an underestimated scenario (small VRC), but that the spatial distribution is very similar (large $\mathrm{R}$ ). Therefore, suitable criteria should be considered for further work.

\section{Correlation between offshore indices and coastal indices}

Figures 7 and 8 represent the correlation between the offshore indices at time $t=5 \mathrm{~min}$ and the coastal indices for Model I. In these figures, the colors of the squares indicating the selected tsunami scenarios are the same as those of Fig. 4c, and the gray crosses indicate the unselected tsunami scenarios. Figure 7 a shows the correlation between the offshore $\operatorname{VRO}(t=5 \mathrm{~min})$ and the coastal VRO. As shown in this figure, most of the coastal VRO values for the selected tsunami scenarios are closer 


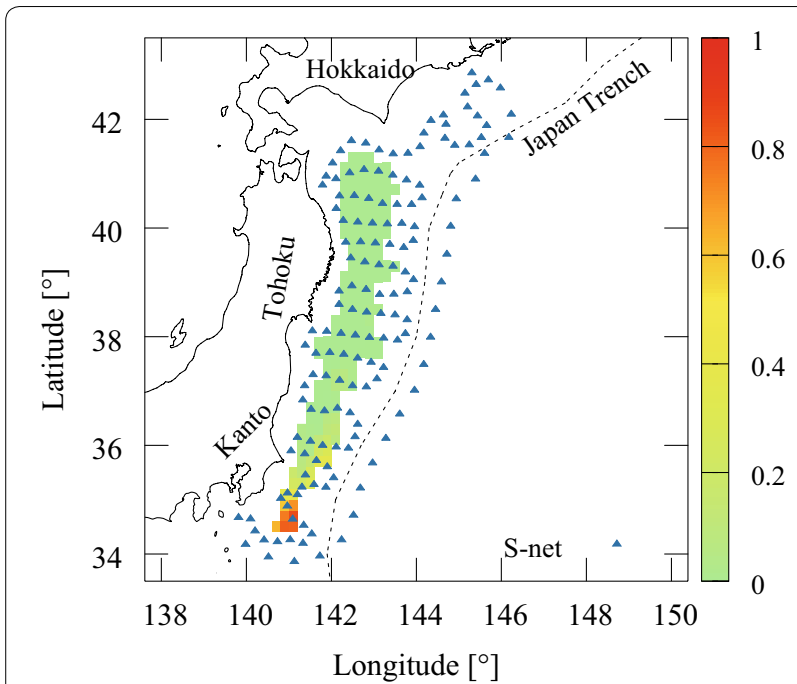

Fig. 5 Color contour map of $R(t=5 \mathrm{~min}$ ) for Model I. $\mathrm{R}$ ( $t=5 \mathrm{~min}$ ) values are plotted at the centroid location of the slip distribution of each fault model registered in the tentative TSB

to 1 than the offshore VRO values for the corresponding tsunami scenarios (coastal VRO $\gtrsim$ offshore VRO $(t=5 \mathrm{~min}))$. As shown in Fig. 7b, the coastal VRC values for all tsunami scenarios are closer to 1 than the offshore VRC values [coastal VRC $\gtrsim$ offshore VRC $(t=5 \mathrm{~min})$ ]. Figure 8 , which presents a diagram showing the correlation between the offshore $\mathrm{R}(t=5 \mathrm{~min})$ and coastal $\mathrm{R}$, indicates that all of the coastal $\mathrm{R}$ values for the selected tsunami scenarios are closer to 1 than the offshore $\mathrm{R}$ $(t=5 \mathrm{~min})$ values [coastal $\mathrm{R} \gtrsim$ offshore $\mathrm{R}(t=5 \mathrm{~min})$ ]. On the other hand, many of the coastal $\mathrm{R}$ values for the unselected tsunami scenarios (gray crosses) are smaller than the offshore $\mathrm{R}$ ( $t=5 \mathrm{~min}$ ) values for the corresponding tsunami scenarios. These tsunami scenarios are not selected, because their variance reductions do not satisfy the thresholds in spite of the good correlation coefficient. Table 1 lists the offshore indices and coastal indices for scenario $\mathrm{A}$, which are represented by the green polygon in Fig. 3 and the green squares in Figs. 4, 6, 7 , and 8. Model Ir, the results of which are included in the comparison in Table 1, is described in the next section. We also calculate the geometric mean $\mathrm{K}$ and geometric standard deviation $\kappa$ defined by Aida (1978) to compare the maximum coastal tsunami height distributions of the pseudo-observation scenario (Model I) with that of scenario A. Therefore, it is possible to select appropriate tsunami scenarios that have maximum tsunami height distributions constrained within the criteria used for the offshore waveform comparison.

\section{Influence of dynamic rupture process (Model Ir)}

Instant rupture propagation is assumed in the previous examination. However, the propagation of a real earthquake tsunami would be delayed due to the dynamic rupture process of the coseismic fault slip (e.g., Hartzell $\mathbf{a}$

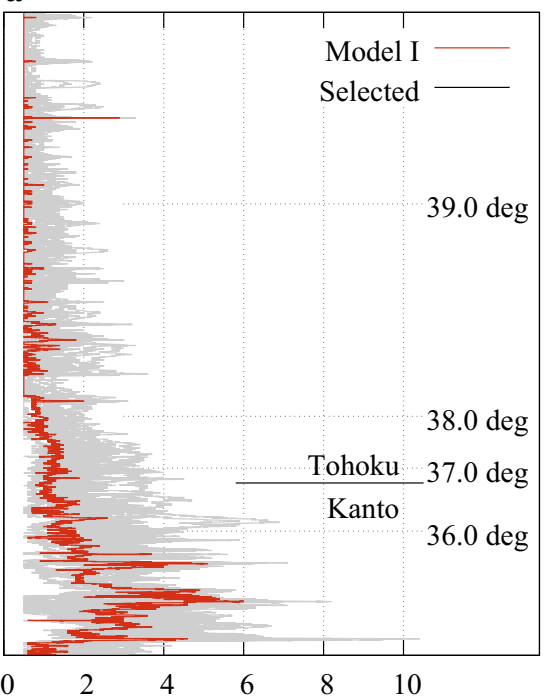

Maximum coastal tsunami height [m] b

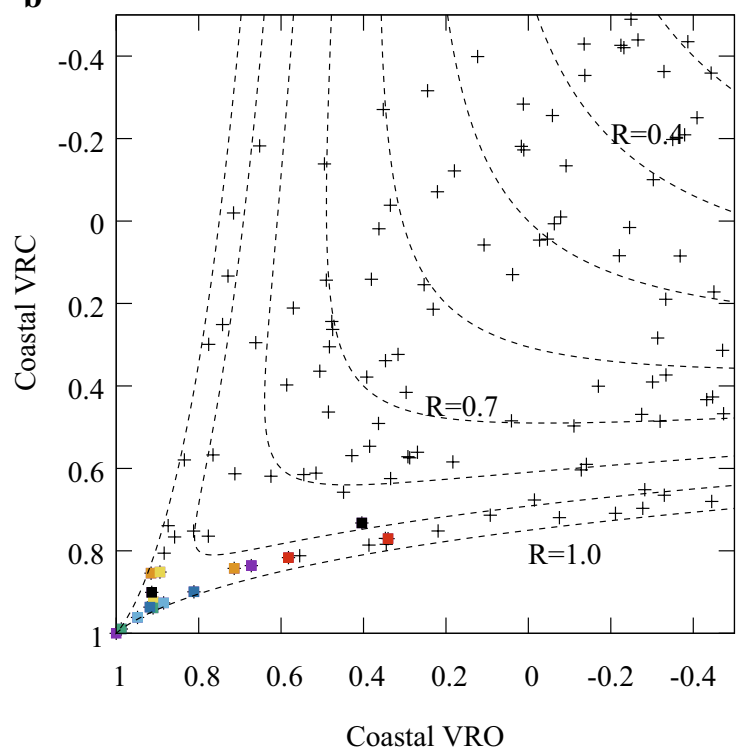

Fig. 6 Evaluations for maximum coastal tsunami height distributions for Model I. a Compares the maximum coastal tsunami height distributions of Model I (red line) along the Pacific coast of Kanto, Tohoku, and Hokkaido shown as the blue line in Fig. 3 with those of 16 selected tsunami scenarios (gray lines) in the background. b The coastal VRO-VRC diagram for comparing maximum coastal tsunami height distributions for the corresponding tsunami scenarios. The colored squares indicate the selected tsunami scenarios in colors that are the same as those in Fig. $4 \mathrm{c}$ 

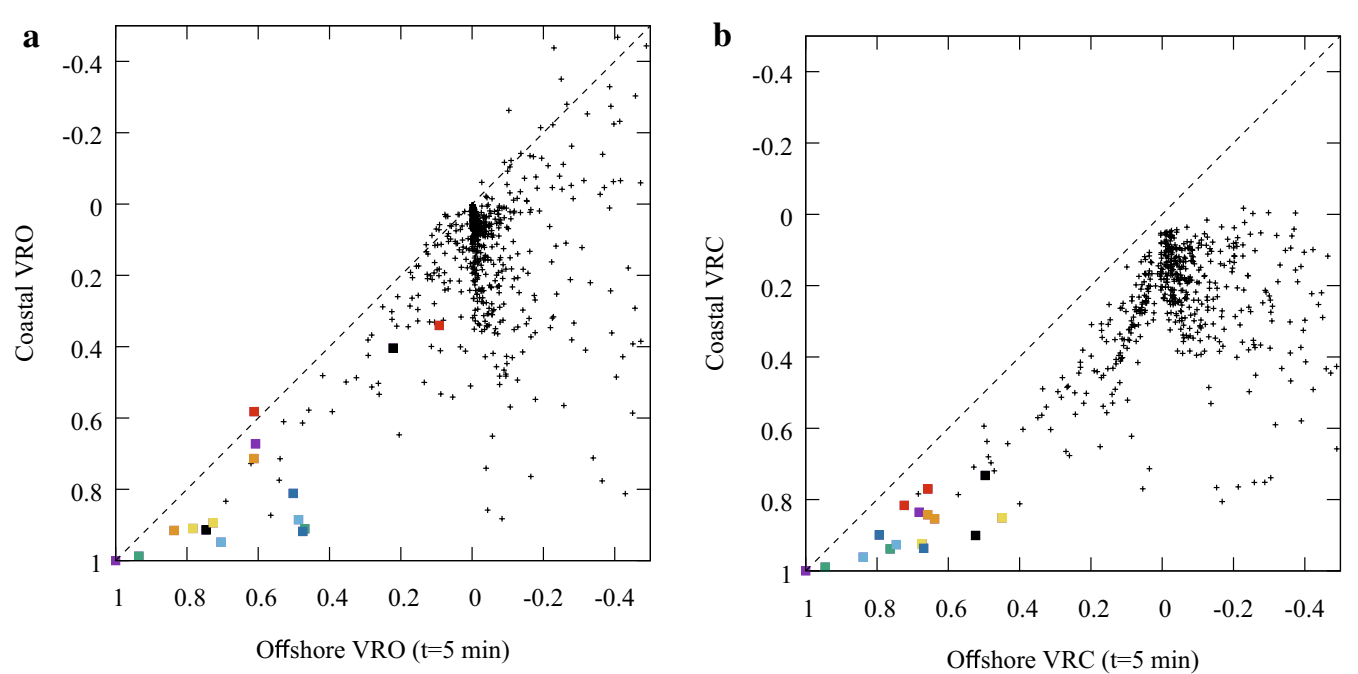

Fig. 7 Correlations between offshore and coastal variance reductions for Model I. a Correlation between offshore VRO ( $t=5 \mathrm{~min})$, derived from a pair of calculated and pseudo-observation offshore waveforms, and coastal VRO, calculated from a pair of calculated and pseudo-observation maximum coastal tsunami height distributions. b Correlation between offshore VRC ( $t=5 \mathrm{~min}$ ) and coastal VRC

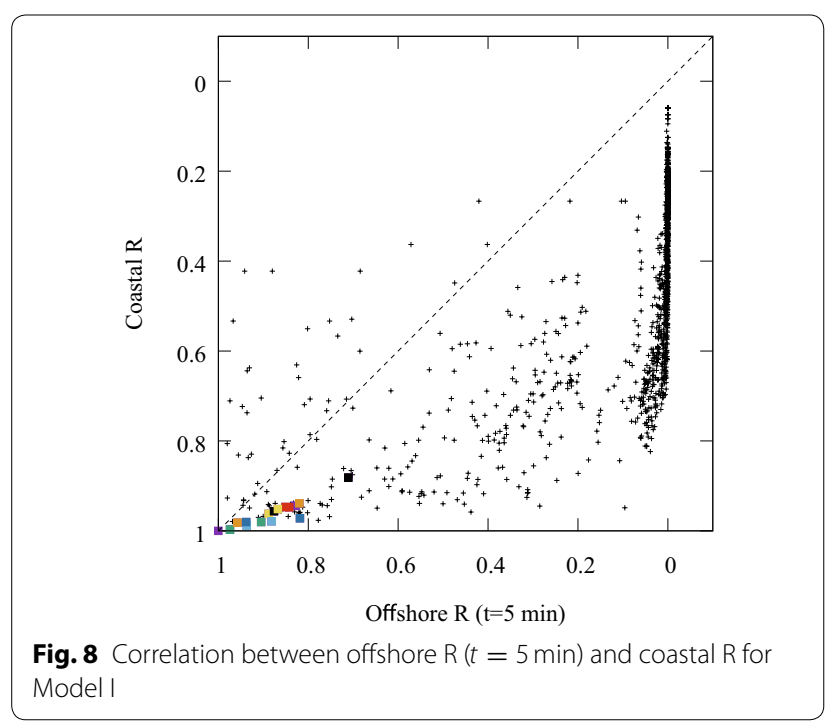

Table 1 Offshore and coastal indices for the best-matched tsunami scenario (scenario $A$ )

\begin{tabular}{llll}
\hline Index & \multicolumn{2}{l}{ Offshore comparison } & \multirow{2}{l}{ Coastal comparison } \\
\cline { 2 - 3 } & Model I & Model Ir & \\
\hline VRO & 0.94 & 0.52 & 0.98 \\
VRC & 0.95 & 0.78 & 0.99 \\
R & 0.97 & 0.92 & 1.00 \\
K & - & - & 0.90 \\
$\kappa$ & - & - & 1.06 \\
\hline
\end{tabular}

This table lists the offshore indices at $t=5 \mathrm{~min}$ and coastal indices by comparing Model I and Ir as the pseudo-observation scenario with scenario A and Heaton 1983; Mulia and Asano 2016). We examine the influence of the dynamic rupture process by modifying Model I to obtain Model Ir by using the convolution between offshore waveforms and a linear ramp function with a rise time of $3 \mathrm{~min}$. For Model Ir, we examine how the multi-index approach works under the same thresholds: VRO $(t=5 \mathrm{~min}) \geq 0.0$, VRC $(t=5 \mathrm{~min}) \geq 0.0$, and $\mathrm{R}(t=5 \mathrm{~min}) \geq 0.7$. As a result, some tsunami scenarios selected in Model I are selected again. Figure 9a shows the offshore VRO-VRC diagram derived from comparisons of the offshore waveforms at $t=5 \mathrm{~min}$. The colored squares indicate the selected tsunami scenarios with colors that are the same as those in the previous results for Model I, e.g., Fig. 4c. The offshore indices for 10 selected tsunami scenarios in this examination are worse than those for Model I in Fig. 4c. The original tsunami scenario (Model I) is selected with VRO $(t=5 \mathrm{~min})=0.80$, $\operatorname{VRC}(t=5 \mathrm{~min})=0.89$, and $\mathrm{R}(t=5 \mathrm{~min})=0.97$. Furthermore, scenario A is selected as a well-matched tsunami scenario again with VRO $(t=5 \mathrm{~min})=0.52$, VRC $(t=5 \mathrm{~min})=0.78$, and $\mathrm{R}(t=5 \mathrm{~min})=0.92$ (Table 1$)$. Figure $9 \mathrm{~b}$ shows the selected tsunami scenario for Model Ir on the coastal VRO-VRC diagram; however, the coastal VRO and coastal VRC values are the same as those for Model I because the maximum coastal tsunami height may not change essentially. As shown in this figure, most of the selected tsunami scenarios are restricted within the region bound by coastal VRO $\geq 0.58$ and coastal VRC $\geq 0.67$. In this examination, therefore, our proposed method is not significantly affected with the rise time of $3 \mathrm{~min}$ at $t=5 \mathrm{~min}$. Moreover, we examine modified Model I with 

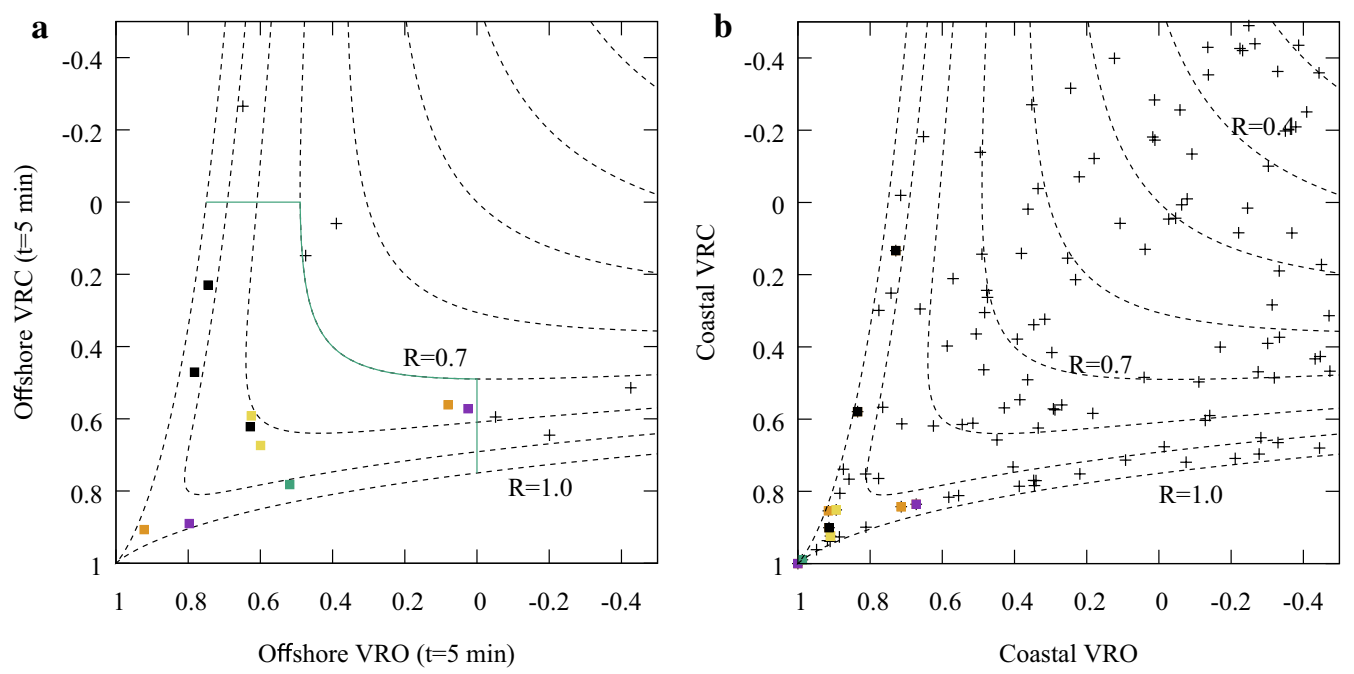

Fig. 9 Offshore and coastal VRO-VRC diagrams for Model Ir. $\mathbf{a}$ is the offshore VRO-VRC diagram for comparing the offshore waveforms at $t=5 \mathrm{~min}$. b plots the selected tsunami scenarios for Model Ir on the coastal VRO-VRC diagram; however, the values of the coastal VROs and VRCs are the same as those for Model I

rise times in the range of $1-5 \mathrm{~min}$. The second column of Table 2 shows the results of three indices comparing Model I and modified Model I for a rise time ranging from $0 \mathrm{~min}$ (no rise time) to $5 \mathrm{~min}$ in steps of $1 \mathrm{~min}$. The result for Model Ir is shown at a rise time of 3 min (fourth line in Table 2). For a rise time of $5 \mathrm{~min}$, however, the original tsunami scenario (Model I) is not selected within the given thresholds due to (VRO ( $t=5 \mathrm{~min}$ ), VRC ( $t=5 \mathrm{~min}$ ), $\mathrm{R}$ $(t=5 \mathrm{~min}))=(-0.06,0.72,0.96)$.

Application of the dynamic rupture process of the coseismic fault slip to the pseudo-observation scenario would delay the tsunami propagation. Therefore, the time-shifted tsunami scenario is expected to match the modified Model I more accurately than the tsunami scenarios without time shift. We evaluate this assumption by defining three time-shifted indices by modifying Eqs. (1), (3), and (4) as follows:

$\mathrm{R}(t, t-\tau)=\frac{\sum_{i=1}^{n} O\left(\boldsymbol{r}_{i}, t\right) C\left(\boldsymbol{r}_{i}, t-\tau\right)}{\sqrt{\sum_{i=1}^{n} O^{2}\left(\boldsymbol{r}_{i}, t\right)} \sqrt{\sum_{i=1}^{n} C^{2}\left(\boldsymbol{r}_{i}, t-\tau\right)}}$

$\operatorname{VRO}(t, t-\tau)=1-\frac{\sum_{i=1}^{n}\left(O\left(\boldsymbol{r}_{i}, t\right)-C\left(\boldsymbol{r}_{i}, t-\tau\right)\right)^{2}}{\sum_{i=1}^{n} O^{2}\left(\boldsymbol{r}_{i}, t\right)}$

$\operatorname{VRC}(t, t-\tau)=1-\frac{\sum_{i=1}^{n}\left(O\left(\boldsymbol{r}_{i}, t\right)-C\left(\boldsymbol{r}_{i}, t-\tau\right)\right)^{2}}{\sum_{i=1}^{n} C^{2}\left(\boldsymbol{r}_{i}, t-\tau\right)}$, where $C\left(\boldsymbol{r}_{i}, t-\tau\right)$ is the time-shifted calculated tsunami waveform, and $\tau$ is the amount by which the time shifted. In this examination, we investigate $\tau=-1,0,1,2,3$, and $4 \mathrm{~min}$ ( $\tau$ should be shorter than $t=5 \mathrm{~min}$ ). Then we calculate $\operatorname{VRO}(t, t-\tau)$, $\operatorname{VRC}(t, t-\tau)$, and $\mathrm{R}(t, t-\tau)$ using time-shifted calculated tsunami scenario $C\left(\boldsymbol{r}_{i}, t-\tau\right)$ for each modified Model I, which has a rise time of $0,1,2$, 3,4 , and $5 \mathrm{~min}$. Based on these examinations, the results of the three indices obtained by comparing Model I and modified Model I are presented in Table 2. As seen in Table 2, a time shift of $\tau=2 \mathrm{~min}$ is the best-matched case for a rise time of $3 \mathrm{~min}$. For a rise time of $5 \mathrm{~min}$, a time shift of $\tau=3$ min could be selected within the given threshold because (VRO ( $t=5 \mathrm{~min})$, VRC ( $t=5 \mathrm{~min}$ ), $\mathrm{R}(t=5 \mathrm{~min}))=(0.93,0.92,0.96)$. The results in Table 2 suggest that $\tau$ of the best-matched case is approximately half of the amount of rise time applied to the pseudoobservation waveform.

Moreover, this approach supports the constraint of the time at which the tsunami originates. In previous examinations, we assumed that the time of origin of the tsunami is known for the purpose of comparing $O\left(\boldsymbol{r}_{i}, t\right)$ and $C\left(\boldsymbol{r}_{i}, t\right)$. However, the time of origin is unknown during a real-time tsunami forecast. As shown in the first line of Table 2, comparisons based on the time shift $\tau$ are consistent with searches for the time of origin. The best-matched case ( $\tau=0 \mathrm{~min})$ provides a well-matched scenario for the time at which the tsunami originated. This examination enables us to confirm that the time at which the tsunami originated could be estimated by the time-shifted comparisons using multiple indices. 
Table 2 The values of the three indices for different rise times and time shift $\tau$

\begin{tabular}{|c|c|c|c|c|c|c|c|}
\hline \multirow[t]{2}{*}{ Rise time } & & \multicolumn{6}{|c|}{ Time shift $\tau$} \\
\hline & & $-1 \min$ & - & $1 \mathrm{~min}$ & $2 \min$ & $3 \min$ & $4 \min$ \\
\hline \multirow[t]{3}{*}{ - } & VRO & 0.98 & $1.00^{\mathrm{a}}$ & 0.97 & 0.88 & 0.62 & 0.32 \\
\hline & VRC & 0.98 & $1.00^{\mathrm{a}}$ & 0.96 & 0.78 & -0.61 & -16.05 \\
\hline & $\mathrm{R}$ & 0.99 & $1.00^{\mathrm{a}}$ & 0.99 & 0.97 & 0.88 & 0.91 \\
\hline \multirow[t]{3}{*}{$1 \mathrm{~min}$} & VRO & 0.94 & 0.98 & 0.99 & 0.93 & 0.68 & 0.36 \\
\hline & VRC & 0.95 & 0.99 & 0.99 & 0.89 & -0.14 & -12.56 \\
\hline & $\mathrm{R}$ & 0.98 & 1.00 & 1.00 & 0.98 & 0.90 & 0.93 \\
\hline \multirow[t]{3}{*}{$2 \min$} & VRO & 0.85 & 0.93 & 0.99 & 0.97 & 0.74 & 0.39 \\
\hline & VRC & 0.91 & 0.95 & 0.99 & 0.96 & 0.25 & -9.61 \\
\hline & $\mathrm{R}$ & 0.97 & 0.99 & 1.00 & 0.99 & 0.93 & 0.94 \\
\hline \multirow[t]{3}{*}{$3 \mathrm{~min}$} & VRO & 0.66 & $0.80^{\mathrm{b}}$ & 0.95 & 0.99 & 0.82 & 0.44 \\
\hline & VRC & 0.84 & $0.89^{b}$ & 0.96 & 0.99 & 0.59 & -6.61 \\
\hline & $\mathrm{R}$ & 0.95 & $0.97^{b}$ & 0.99 & 0.99 & 0.95 & 0.95 \\
\hline \multirow[t]{3}{*}{$4 \min$} & VRO & 0.30 & 0.51 & 0.80 & 0.96 & 0.89 & 0.51 \\
\hline & VRC & 0.75 & 0.81 & 0.90 & 0.97 & 0.82 & -3.87 \\
\hline & $\mathrm{R}$ & 0.93 & 0.96 & 0.98 & 0.99 & 0.96 & 0.96 \\
\hline \multirow[t]{3}{*}{$5 \mathrm{~min}$} & VRO & -0.40 & -0.06 & 0.46 & 0.80 & 0.93 & 0.59 \\
\hline & VRC & 0.67 & 0.72 & 0.81 & 0.90 & 0.92 & -1.74 \\
\hline & $\mathrm{R}$ & 0.93 & 0.96 & 0.98 & 0.99 & 0.96 & 0.96 \\
\hline
\end{tabular}

The values in italics face indicate the best-matched $\tau$ for each synthetic rise time

a Result of the examination for Model I (Fig. 4c)

b Result of the examination for Model Ir (Fig. 9a)

\section{Examination of 2011 Tohoku earthquake tsunami (Model II)} In the pseudo-observation scenario chosen from the tentative TSB, the pseudo-observation waveform may be well matched with some tsunami scenarios stored in the tentative TSB, because similar fault models are found in the tentative TSB (Table 1). When the variance reduction is larger than 0.7 , these scenarios are generally recognized to be matched (e.g., Tanioka et al. 1995; Baba and Cummins 2005). On the other hand, the slip distribution for a real earthquake source is usually more complex than the characterized fault models registered in the tentative TSB. Therefore, to test our method for a more realistic tsunami source model, we calculate tsunami waveforms by using the slip distribution of the 2011 Tohoku earthquake, suggested by the Cabinet Office (2012) as a pseudo-observation scenario (Model II). Although this source model was estimated by considering the effect of the rupture process on the fault plane, we assume that the coseismic crustal deformation is immediately completed at time $t=0$ in order to focus on the influence of the complexity of the fault model. We use the same thresholds: $\operatorname{VRO}(t=5 \mathrm{~min}) \geq 0.0, \operatorname{VRC}(t=5 \mathrm{~min}) \geq 0.0$, and $\mathrm{R}(t=5 \mathrm{~min}) \geq 0.7$, as in the previous examinations.

Figure 10a compares the pseudo-observation waveform $O\left(\boldsymbol{r}_{i}, t=5 \mathrm{~min}\right)$ with the waveform $C\left(\boldsymbol{r}_{i}, t=5 \mathrm{~min}\right)$ of the best-matched tsunami scenario, which is represented by the purple square shown at (VRO $(t=5 \mathrm{~min})$, $\operatorname{VRC}(t=5 \mathrm{~min}), \mathrm{R}(t=5 \mathrm{~min}))=(0.66,0.67,0.83)$ in Fig. 10c. Figure 10b compares the converted pseudoobservation waveforms with the waveform of the bestmatched tsunami scenario. Figure $10 \mathrm{c}$, d represents offshore VRO-VRC diagrams for 50 selected tsunami scenarios and others $5 \mathrm{~min}$ after the earthquake. The number of selected tsunami scenarios is larger than that in the previous examination, because the tentative TSB is constructed with a bias toward tsunami scenarios for large earthquakes, such as the tsunami caused by the 2011 Tohoku earthquake. As shown in Fig. 10d, the values of VRC ( $t=5 \mathrm{~min}$ ) for many unselected tsunami scenarios are strongly negative. This indicates that the 2011 Tohoku earthquake tsunami is close to the maximum class of tsunami scenarios registered in the tentative TSB, i.e., many tsunami scenarios registered in the tentative TSB are rejected due to underestimations. Figure 11 is a color contour map for $\mathrm{R}(t=5 \mathrm{~min})$ plotted at the centroid location of the slip distribution of fault models registered in the TSB. The figure shows that the distribution of $\mathrm{R}(t=5 \mathrm{~min})$ values is approximately consistent with the fault slip distributions proposed by Cabinet Office (2012) and obtained by the other 

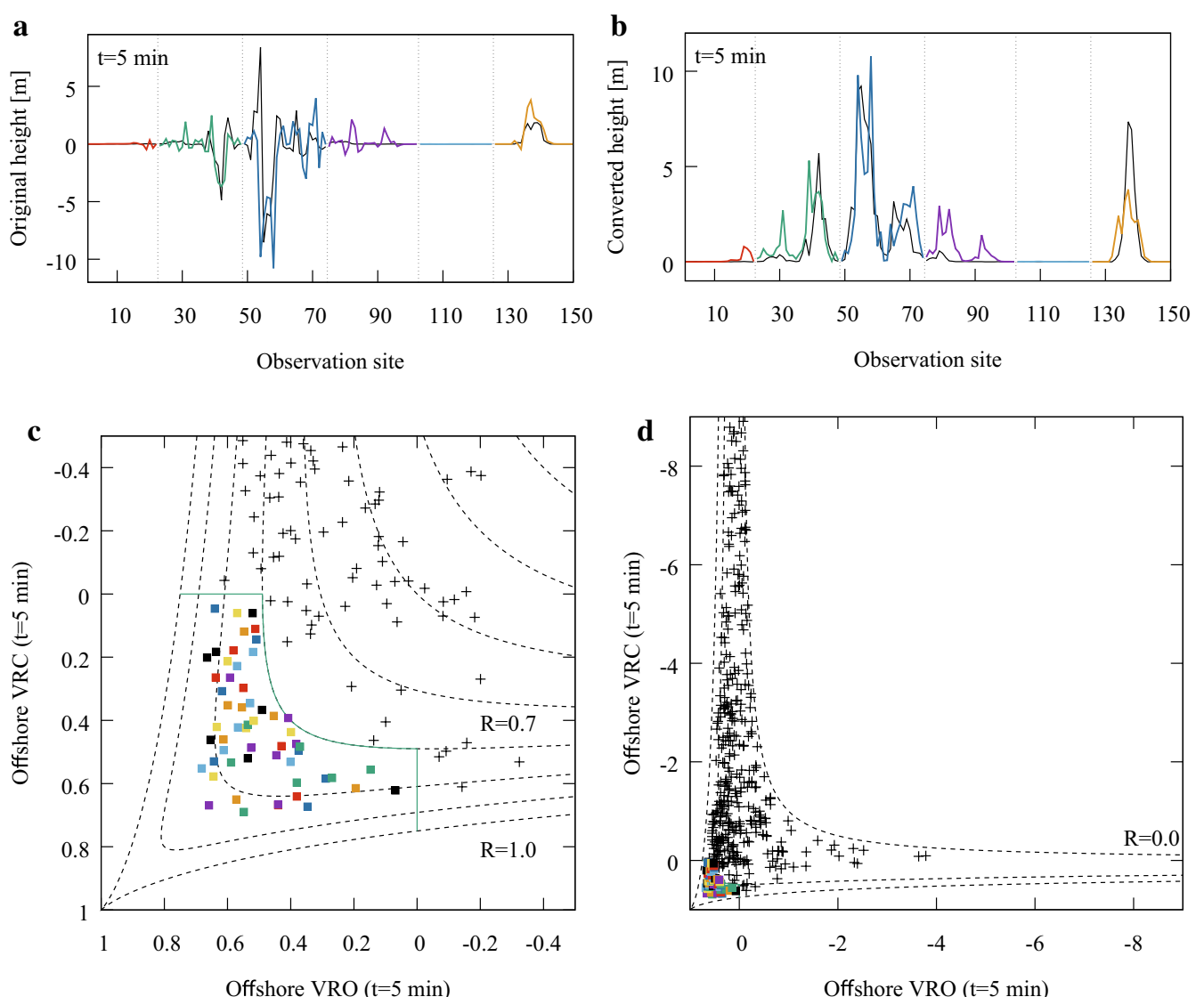

Fig. 10 Offshore comparisons at 5 min after the occurrence of an earthquake for Model II. $\mathbf{a}$, b Compare the tsunami height distributions of Model II (colored lines) with those of the best-matched scenario (gray line), which is represented by the purple square in $\mathbf{c}$. c, $\mathbf{d}$ A close-up plot and wide view of the VRO-VRC diagram, respectively (see also the caption of Fig. 4)

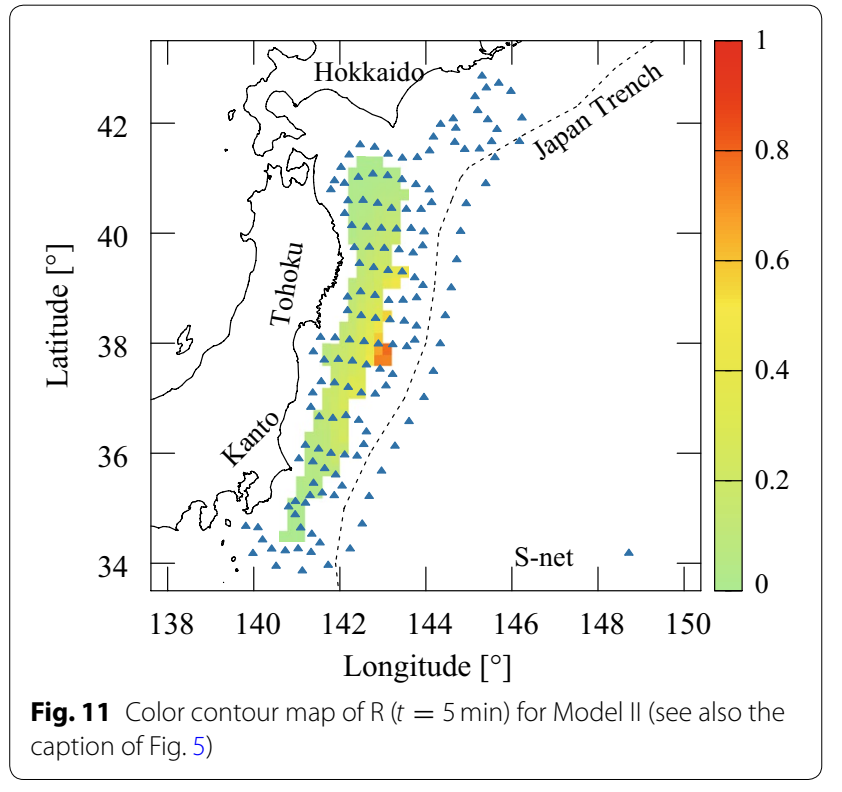

inversion results (e.g., Fujii et al. 2011; Satake et al. 2013; Hossen et al. 2015).

Figure 12 shows the evaluations for the maximum coastal tsunami height distribution of Model II. Figure $12 \mathrm{a}$ indicates the maximum coastal tsunami height distribution of Model II and 50 selected tsunami scenarios. Figure $12 \mathrm{~b}$ plots the selected tsunami scenarios on the coastal VRO-VRC diagram. In this figure, the colored squares, of which the colors indicate the same scenarios as those in Fig. 10c, indicate the selected tsunami scenarios. We confirm that our method can select tsunami scenarios appropriately for the pseudo-observation scenario calculated from the complex fault model, because the selected tsunami scenarios satisfy coastal $\mathrm{VRO} \geq 0.69$, coastal VRC $\geq 0.57$, and coastal $R \geq 0.87$ (Fig. 12b). However, there are no tsunami scenarios, whose offshore variance reductions, VRO and VRC, are larger than 0.7 (Fig. 10c). By comparing Figs. 10c and 12b, we conclude that the coastal VRO and VRC values for all 


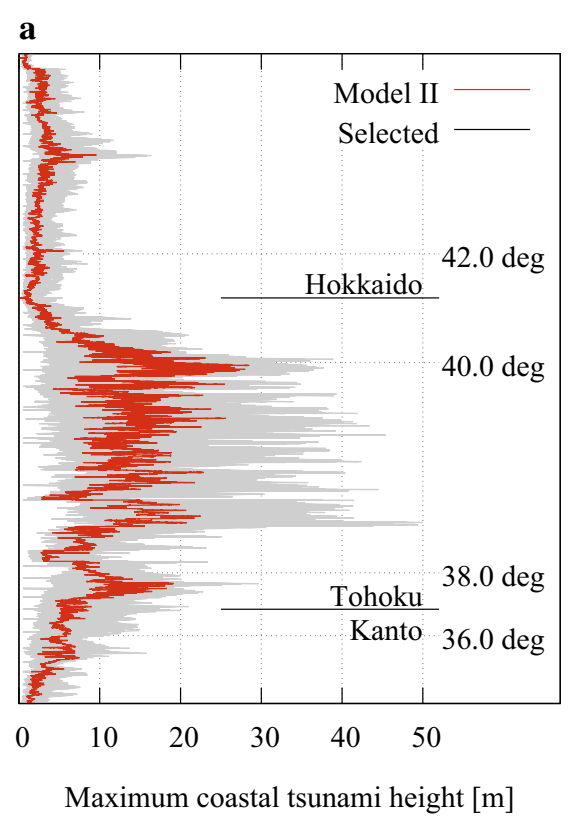

\section{b}

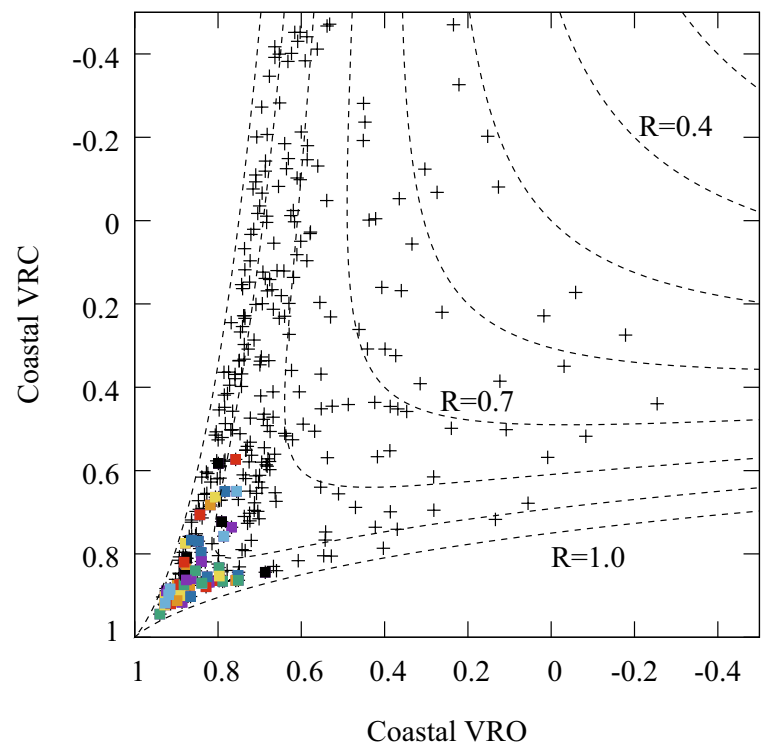

Fig. 12 Evaluation of maximum coastal tsunami height distributions for Model II. a Compares the maximum coastal tsunami height distributions of Model II (red line) along the target coastline with 50 selected tsunami scenarios (gray lines) in the background. b The coastal VRO-VRC diagram for comparing the maximum coastal tsunami height distributions for the corresponding tsunami scenarios. The colored squares indicate the selected tsunami scenarios in colors with the same meaning as those in Fig. 10c, d

the selected tsunami scenarios are reduced by a larger amount than the offshore $\operatorname{VRO}(t=5 \mathrm{~min})$ and VRC $(t=5 \mathrm{~min})$ values.

\section{Effectiveness of using multiple indices}

We investigate the effectiveness of using three indices simultaneously by using only one index for Model II when selecting tsunami scenarios. In general, the variance reduction normalized by observation has been used for comparing observed and calculated data (e.g., Chi et al. 2001; Kubo et al. 2002; Ktenidou et al. 2011). Therefore, we examine the case of using only $\operatorname{VRO}(t)$ defined by Eq. (3) with a threshold of $\operatorname{VRO}(t=5 \mathrm{~min}) \geq 0.0$. For this examination, we selected the smallest tsunami scenarios (Mw 7.0) with a large negative value of VRC $(t=5 \mathrm{~min})$ from the tentative TSB. If only $\operatorname{VRO}(t)$ is used as an index, underestimated tsunami scenarios could be selected and forecast. Even if we were to use the stricter threshold VRO $(t=5 \mathrm{~min}) \geq 0.5$, the underestimated tsunami scenario (Mw 8.6) would still be selected; its VRO $(t=5 \mathrm{~min})$ is 0.515 , but its $\operatorname{VRC}(t=5 \mathrm{~min})$ is -0.972 .

We avoid such an underestimation by presuming that it is effective to use both $\operatorname{VRO}(t)$ and $\operatorname{VRC}(t)$ simultaneously instead of using only $\operatorname{VRO}(t)$. A more effective approach to eliminating underestimated tsunami scenarios would be to set a stricter threshold for $\operatorname{VRC}(t)$, for example, $\operatorname{VRO}(t) \geq 0.0$ and $\operatorname{VRC}(t) \geq 0.5$. As we described above, the correlation coefficient $\mathrm{R}(t)$ facilitates the constraint of the tsunami source location. Therefore, we conclude that the combination of three indices rather than a single index allows us to achieve a more accurate tsunami forecast. However, by setting the threshold for $\mathrm{R}(t)$, we notice that the threshold $\mathrm{R}(t) \geq 0.7$ is not effective with $\operatorname{VRO}(t) \geq 0.5$ and $\operatorname{VRC}(t) \geq 0.5$, because $\mathrm{R}(t)$ always satisfies $\mathrm{R}(t) \geq 0.75$. When $\operatorname{VRO}(t) \geq 0.0$ and $\operatorname{VRC}(t) \geq 0.0$ are used as thresholds, $\mathrm{R}(t)$ always satisfies $\mathrm{R}(t) \geq 0.5$. Therefore, we suggest that the thresholds for the two variance reductions, $\operatorname{VRO}(t)$ and $\operatorname{VRC}(t)$, are defined first to constrain the tsunami size. Then, the threshold for the correlation coefficient $\mathrm{R}(t)$ is defined to constrain the tsunami source location.

\section{Conclusions}

In this paper we propose a new method for achieving realtime tsunami forecasts. The method uses multiple indices to select appropriate tsunami scenarios by comparing waveforms that were observed offshore with those that are pre-calculated and registered in the TSB. We applied our method to a Mw 8.0 earthquake that occurred off the Boso Peninsula that was registered in the tentative TSB and the 2011 Tohoku earthquake as pseudo-observation scenarios. These examinations enabled us to confirm that appropriate tsunami scenarios could be selected by using 
the three indices, which consist of two kinds of variance reductions and a correlation coefficient, with offshore waveforms obtained by both pseudo-observation and by calculation, both of which are derived from oceanbottom pressure changes. Mathematical considerations and synthetic examinations revealed that two different kinds of variance reductions, $\operatorname{VRO}(t)$ and $\operatorname{VRC}(t)$, which are normalized by the L2-norm of either the observed or calculated waveforms, are sensitive to overestimation or underestimation of the tsunami size. We also found the correlation coefficient $\mathrm{R}(t)$ to be sensitive to the spatial distribution of the offshore tsunami, i.e., it is sensitive to the tsunami source location. Therefore, we concluded that the use of a combination of three indices rather than a single index is promising for providing more accurate tsunami forecasts. Furthermore, we investigated the correlations between offshore indices, derived from comparisons of offshore tsunami waveforms, and coastal indices, calculated from comparisons of maximum coastal tsunami height distributions. We found that it is possible to select appropriate tsunami scenarios that have maximum coastal tsunami height distributions constrained within the criteria used for the offshore waveform comparison. In addition, we suggested defining the thresholds for $\operatorname{VRO}(t)$ and $\operatorname{VRC}(t)$ first to constrain the tsunami size, followed by the determination of the threshold for $\mathrm{R}(t)$ to constrain the location of the tsunami source. We showed that, by comparing offshore waveforms, our method can select appropriate tsunami scenarios whose maximum coastal tsunami height distributions are close to those of the pseudo-observation scenario. By adding tsunami inundation components, such as the inundation area and run-up heights to the TSB, our method can be expanded for real-time tsunami inundation forecasts.

\section{Abbreviations}

TSB:Tsunami Scenario Bank; S-net: the Seafloor Observation Network for Earthquakes and Tsunamis along the Japan Trench; GNSS: Global Navigation Satellite System; VRO: variance reduction normalized by observation; VRC: variance reduction normalized by calculation.

\section{Authors' contributions}

NY proposed the ideas for this study, analyzed the data, and drafted the manuscript. SA initiated and managed the project, which is supported by SIP and related to this study. SA and KH prepared the data used in this study. All authors participated extensively in the design of this method and revisions of the manuscript. All authors read and approved the final manuscript.

\section{Acknowledgements}

We thank Editor Takuto Maeda and two anonymous reviewers for their thorough reviews and valuable suggestions on improving the quality of this article. This work was supported in part by the Council for Science, Technology, and Innovation (CSTI) through the Cross-ministerial Strategic Innovation Promotion Program (SIP), entitled "Enhancement of societal resiliency against natural disasters" (Funding agency: JST)

\section{Competing interests}

The authors declare that they have no competing interests.
Received: 23 January 2016 Accepted: 29 June 2016

Published online: 22 July 2016

\section{References}

Aida I (1978) Reliability of a tsunami source model derived from fault parameters. J Phys Earth 26(1):57-73

Baba T, Cummins PR (2005) Contiguous rupture areas of two Nankai Trough earthquakes revealed by high-resolution tsunami waveform inversion. Geophys Res Lett 32(8):L08305

Baba T, Takahashi N, Kaneda Y (2014) Near-field tsunami amplification factors in the Kii Peninsula, Japan for Dense Oceanfloor Network for Earthquakes and Tsunamis (DONET). Mar Geophys Res 35(3):319-325

Benavente R, Cummins PR (2013) Simple and reliable finite fault solutions for large earthquakes using the w-phase: the Maule $(\mathrm{mw}=8.8)$ and Tohoku $(m w=9.0)$ earthquakes. Geophys Res Lett 40(14):3591-3595

Blewitt G, Hammond WC, Kreemer C, Plag HP, Stein S, Okal E (2009) Gps for real-time earthquake source determination and tsunami warning systems. J Geod 83(3-4):335-343

Cabinet Office, Government of Japan (2012) Tsunami source model of 2011 Tohoku earthquake tsunami (in Japanese). http://www.bousai.go.jp/ jishin/nankai/model/12/pdf/sub_1.pdf. Accessed 28 Dec 2015

Chi WC, Dreger D, Kaverina A (2001) Finite-source modeling of the 1999 Taiwan (Chi-Chi) earthquake derived from a dense strong-motion network. Bull Seismol Soc Am 91(5):1144-1157

Fujii Y, Satake K, Sakai S, Shinohara M, Kanazawa T (2011) Tsunami source of the 2011 off the Pacific coast of Tohoku earthquake. Earth Planets Space 63(7):815-820

Gusman AR, Tanioka Y (2014) W phase inversion and tsunami inundation modeling for tsunami early warning: case study for the 2011 Tohoku event. Pure Appl Geophys 171(7):1409-1422

Gusman AR, Tanioka Y, Maclnnes BT, Tsushima H (2014) A methodology for near-field tsunami inundation forecasting: application to the 2011 Tohoku tsunami. J Geophys Res Solid Earth 119(11):8186-8206

Hartzell SH, Heaton TH (1983) Inversion of strong ground motion and teleseismic waveform data for the fault rupture history of the 1979 Imperial Valley, California, earthquake. Bull Seismol Soc Am 73(6A):1553-1583

Hirata K, Fujiwara H, Nakamura H, Osada M, Ohsumi T, Morikawa N, Kawai S, Aoi S, Yamamoto N, Matsuyama H, Toyama N, Kito T, Murashima Y, Murata Y, Inoue T, Saito R, Akiyama S, Korenaga M, Abe Y, Hashimoto N (2014) Nationwide tsunami hazard assessment project in Japan. In: Abstract NH12A-03 presented at 2014 Fall Meeting, AGU, San Francisco, CA, 15-10 Dec

Hossen MJ, Cummins PR, Dettmer J, Baba T (2015) Tsunami waveform inversion for sea surface displacement following the 2011 Tohoku earthquake: importance of dispersion and source kinematics. J Geophys Res Solid Earth 120(9):6452-6473

Kamigaichi O (2009) Tsunami forecasting and warning. In: Meyers RA (ed) Encyclopedia of complexity and systems science. Springer, Berlin, pp 9592-9618

Kanamori H (1972) Mechanism of tsunami earthquakes. Phys Earth Planet Inter 6(5):346-359

Kanamori H (1993) W phase. Geophys Res Lett 20(16):1691-1694

Kanazawa T (2013) Japan Trench earthquake and tsunami monitoring network of cable-linked 150 ocean bottom observatories and its impact to earth disaster science. In: 2013 IEEE international underwater technology symposium (UT). IEEE, pp 1-5

Kaneda Y, Kawaguchi K, Araki E, Sakuma A, Matsumoto H, Nakamura T, Kamiya S, Ariyoshi K, Baba T, Ohori M, Hori T (2009) Dense Ocean floor Network for Earthquakes and Tsunamis (DONET) — development and data application for the mega thrust earthquakes around the Nankai Trough. In: AGU Fall Meeting abstracts, vol 1, p 1453

Koshimura S, Hino R, Ohta Y, Kobayashi H, Musa A, Murashima Y (2014) Realtime tsunami inundation forecasting and damage mapping towards enhancing tsunami disaster resiliency. In: Abstract MH23B-05 presented at 2014 Fall Meeting, AGU, San Francisco, CA, 15-10 Dec

Ktenidou OJ, Chávez-García FJ, Pitilakis KD (2011) Variance reduction and signal-to-noise ratio: reducing uncertainty in spectral ratios. Bull Seismol Soc Am 101(2):619-634 
Kubo A, Fukuyama E, Kawai H, Nonomura K (2002) NIED seismic moment tensor catalogue for regional earthquakes around Japan: quality test and application. Tectonophysics 356(1):23-48

Maeda T, Obara K, Shinohara M, Kanazawa T, Uehira K (2015) Successive estimation of a tsunami wavefield without earthquake source data: a data assimilation approach toward real-time tsunami forecasting. Geophys Res Lett 42(19):7923-7932

Mulia IE, Asano T (2016) Initial tsunami source estimation by inversion with an intelligent selection of model parameters and time delays. J Geophys Res Oceans 121(1):441-456

Ohta Y, Kobayashi T, Tsushima H, Miura S, Hino R, Takasu T, Fujimoto H, linuma T, Tachibana K, Demachi T et al (2012) Quasi real-time fault model estimation for near-field tsunami forecasting based on RTK-GPS analysis: application to the 2011 Tohoku-Oki earthquake (mw 9.0). J Geophys Res Solid Earth 117(B2):B02311

Oishi Y, Imamura F, Sugawara D (2015) Near-field tsunami inundation forecast using the parallel TUNAMI-N2 model: application to the 2011 TohokuOki earthquake combined with source inversions. Geophys Res Lett 42(4):1083-1091

Okada Y (1985) Surface deformation due to shear and tensile faults in a halfspace. Bull Seismoll Soc Am 75(4):1135-1154

Satake K, Fujii Y, Harada T, Namegaya Y (2013) Time and space distribution of coseismic slip of the 2011 Tohoku earthquake as inferred from tsunami waveform data. Bull Seismol Soc Am 103(2B):1473-1492
Tanioka Y, Satake K, Ruff L (1995) Total analysis of the 1993 Hokkaido NanseiOki earthquake using seismic wave, tsunami, and geodetic data. Geophys Res Lett 22(1):9-12

Tatehata H (1997) The new tsunami warning system of the Japan meterological agency. Tsunami Hazards 16(1):39-49

Tatsumi D, Tomita T (2013) Development and implementation of real-time tsunami inundation prediction method. J Jpn Soc Civ Eng Ser B2 Coast Eng 69(1):34-47 (in Japanese with English abstract)

Tsushima H, Ohta Y (2014) Review on near-field tsunami forecasting from offshore tsunami data and onshore GNSS data for tsunami early warning. J Disaster Res 9(3):339-357

Tsushima H, Hino R, Fujimoto H, Tanioka Y, Imamura F (2009) Near-field tsunami forecasting from cabled ocean bottom pressure data. J Geophys Res Solid Earth 114(B6):B03311

Uehira K, Kanazawa T, Noguchi S, Aoi S, Kunugi T, Matsumoto T, Okada Y, Sekiguchi S, Shiomi K, Shinohara M, Yamada T (2012) Ocean bottom seismic and tsunami network along the Japan Trench. In: Abstract OS41C-1736 presented at 2012 Fall Meeting, AGU, San Francisco, CA, 3-7 Dec

Yamamoto N, Hirata K, Aoi S, Suzuki W, Nakamura H, Kunugi T (2016) Rapid estimation of tsunami source centroid location using a dense offshore observation network. Geophys Res Lett 43(9):4263-4269

\section{Submit your manuscript to a SpringerOpen ${ }^{\circ}$ journal and benefit from:}

- Convenient online submission

- Rigorous peer review

- Immediate publication on acceptance

- Open access: articles freely available online

- High visibility within the field

- Retaining the copyright to your article

Submit your next manuscript at springeropen.com 